\title{
Differential human impact on the survival of genetically distinct avian lineages
}

\author{
AUSTIN L. HUGHES
}

\begin{abstract}
Summary
At the present time the earth is facing an anthropogenic (human-caused) mass extinction event that may eventually rival previous mass extinction events caused by drastic changes in the physical environment; however, the impact of this event on the earth's biotic diversity remains difficult to predict. Patterns of extinction and endangerment in birds, one of the best known taxonomically among major groups of organisms, showed that the distribution of human impact has been non-uniform relative to phylogenetic relationships. Fifteen major avian lineages differed over 35 -fold with respect to the frequency of historical extinction and over threefold with respect to frequency of current threat; and overall rates of both extinction and threat were significantly higher in non-passerine orders than in passerines. Moreover, among both passerines and non-passerines, the rate of historic extinction has been significantly higher for species in monotypic genera than for other species; and in passerines, the rate of current threat is significantly higher for species in monotypic genera than for other species. Thus, the anthropogenic extinction and threat to avian species has specifically targeted species that are phylogenetically and thus, presumably genetically, unique.
\end{abstract}

\section{Introduction}

Although mass extinction events have occurred more than once in the history of life on earth, the current mass extinction event is unique in being due entirely to the activities of one species, Homo sapiens. Because of the unique causality of this anthropogenic extinction event and because of our imperfect knowledge of either the causes or the effects of previous mass extinction events, it is difficult to estimate the ultimate impact of ongoing extinctions on the totality of life on earth (Diamond 1989, Smith et al. 1993, Bibby 1995, Pimm et al. 1995, Samways 1996, Seehausen et al. 1997, Vazquez and Gittleman 1998). If only for purely pragmatic reasons, based on the potential of biological species as sources of medically or industrially useful compounds, it has been argued that it is important to preserve as much as possible of the genetic diversity represented by living species (Oldfield 1984, Kunin and Lawton 1996). Nee and May (1997) have recently shown that a pattern of random extinction of species in a phylogeny will conserve nearly as much of its evolutionary history as will a strategy designed to maximize the amount of evolutionary history that is preserved. Their analysis might appear to provide a basis for optimism regarding the outcome of the current mass extinction, given economic and political limits on human ability to implement strategies for preserving genetic diversity. However, it remains 
unclear whether anthropogenic extinction is a random process relative to phylogeny in different groups of organisms (McKinney 1997).

Of major animal taxa, birds have long been the best known at the species level (Sibley and Monroe 1990). Recent molecular studies, though not resolving all taxonomic problems, have made birds the best known of vertebrate classes at higher levels as well (Sibley and Ahlquist 1990). The fact that the relationships among birds are well known makes it possible to assess the relative impact of human-caused extinction and endangerment on genetically distinct lineages. Recently a number of studies have examined the randomness of human impact on the survival of different taxonomic groups of birds. Bennett and Owens (1997) presented evidence that extinction is not randomly distributed among avian families. Gaston and Blackburn (1997) found differences among tribes with respect to proportion of species currently under threat of extinction, and their results showed a positive relationship between the proportion of species threatened and an estimate of the evolutionary age of the tribe. Russell et al. (1998) reported that, in both birds and mammals, extinctions have been selective with respect to genus, with a disproportionate effect on genera with smaller numbers of species.

The present study examines levels of both extinction in historical times and current threat across the major evolutionary lineages of birds, as determined by DNA-DNA hybridization (Sibley and Ahlquist 1990), in order to test whether these lineages have suffered human impact uniformly. In addition, I examine further the question of a differential human impact on genera of different sizes (Russell et al. 1998). Because a monotypic (single-species) genus is expected to have a unique genetic heritage, differential anthropogenic effects on species in monotypic genera would be indicative of a pattern that is non-uniform with respect to the genetic information incorporated in the phylogeny of birds. Thus, I compare levels of historical extinction and current threat in monotypic genera with those in more species-rich genera.

\section{Methods}

I analysed occurrences of historic extinction (extinction during or after the period of European colonization beginning in the fifteenth century) and current threat in 9699 species of birds. Species were recognized following Sibley and Monroe (1990, 1993); species recognized by Collar et al. (1994) but not by Sibley and Monroe (1990,1993), including species discovered since Sibley and Monroe (1993), were not included. Current threat was defined to include the categories vulnerable, endangered, and critical in the listing of Collar et al. (1994). Extinction was defined following Sibley and Monroe (1990, 1993), except for two species (Dicaeum quadricolor and Neospiza concolor) listed as rediscovered by Collor et al. (1994). Sibley and Ahlquist's (1990) DNA-DNA hybridization based phylogeny of avian higher categories was assumed. Fifteen major avian lineages were compared. These lineages were chosen because each is represented by a substantial number of living species and because the distinctiveness of each lineage is well supported by the DNA-DNA hybridization data (Sibley and Ahlquist 1990). This comparison was used to assess whether rates of extinction and threat are similar across these genetically differentiated lineages. Then I compared rates of extinction and current threat for species in monotypic (single-species) genera with 


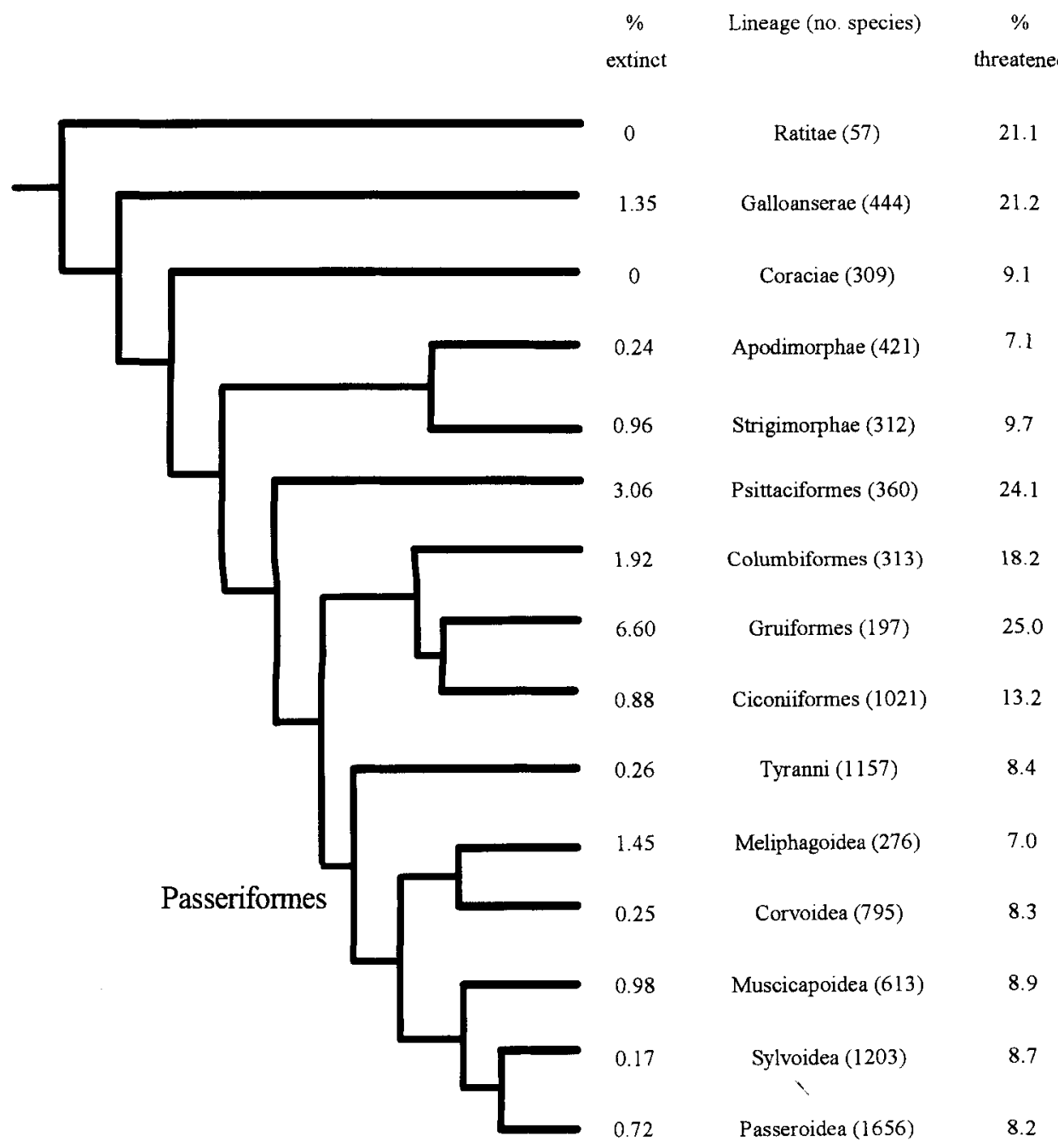

Figure 1. Percentage of historical extinctions and percentage threatened among extant species in 15 major lineages of birds.

those of species in genera including two or more species separately for passerine (Passeriformes) and non-passerine birds.

\section{Results}

Fifteen major lineages of birds were compared with respect to the proportion of species that have become extinct in historical times and the proportion of living species subject to a current threat of extinction (Figure 1). Two lineages (Ratitae, Coraciae) had no historic extinctions, and others had very few (e.g., Sylvoidea) (Figure 1). By contrast, other lineages (especially Psittaciformes and Gruiformes) have experienced substantial levels of extinction. Levels of threat were less varied 
among lineages than were levels of extinction, with all lineages showing at least $7 \%$ of species threatened (Figure 1 ). However, in the lineages with the greatest proportions of species threatened (again Psittaciformes and Gruiformes) nearly $25 \%$ of extant species are threatened (Figure 1). For all 15 lineages, the proportion of species that have become extinct was significantly positively correlated with the proportion of extant species considered threatened $(r=0.672 ; P<0.01)$. There were two major exceptions to this overall trend: Ratitae and Meliphagoidea. Ratitae have no historical extinctions, but $21.1 \%$ of species are threatened. It is worth mentioning however, that the extinction of the New Zealand moas, though not included in the analysis because it occurred prior to the historical period, was almost certainly anthropogenic in origin (Cooper et al. 1993). Meliphagoidea have the lowest proportion of currently threatened species $(7.0 \%)$ but a relatively high proportion of historically extinct species (1.45\%) (Figure 1).

A single order, Passeriformes (passerine birds) contains $59 \%$ of living species. When patterns were compared to non-passerines of all orders, the latter showed significantly higher levels of both historical extinction (1.4\% vs. $0.5 \%$ ) and current threat (13.8\% vs. $8.7 \%$ ) (Figure 2).

Separately for passerines and non-passerines, levels of historical extinction and current threat were compared for species from monotypic genera and species from genera containing two or more species (Figure 2). For both passerines and non-passerines, species from monotypic genera had significantly higher extinction rates than those belonging to more species-rich genera (Figure 2). Note that these results do not fit Jablonski's (1986) model of a background level of extinction leading to loss of species-poor clades, because that model requires that species-rich and species-poor clades be exposed to similar extinction rates. In passerines, a significantly higher proportion of extant species from monotypic genera are threatened than of those from more species-rich genera (Figure 2). This latter pattern is not seen in non-passerines, in which all groups received equally high levels of threat (Figure 2).

\section{Discussion}

Given known factors associated with human impact on survival of avian species, it is not surprising that different major taxonomic groups have been affected differently. For example, Gruiformes include a number of species of islandendemic rails (Rallidae) which have been particularly susceptible to various human activities (hunting, introduction of mammalian predators) (Johnson and Stattersfield 1990). Gruiformes also include cranes (Gruidae), which have been affected by destruction of continental wetland habitat as well as, because of their large size and conspicuousness, hunting by humans (Meine and Archibald 1996). Psittaciformes (parrots) include numerous island endemics plus species that have been strongly impacted by the cage bird trade (Collar and Juniper 1992).

The fact that for the 15 major lineages rates of historical extinction and current threat are positively correlated suggests that certain factors implicated in their survival have persisted for a long time, perhaps three to four centuries (the period of the anthropogenic extinction). However, the fact that the correlation is not perfect suggests that for some taxa these factors may change over time. For example, Meliphagoidea have experienced a relatively high rate of historical 

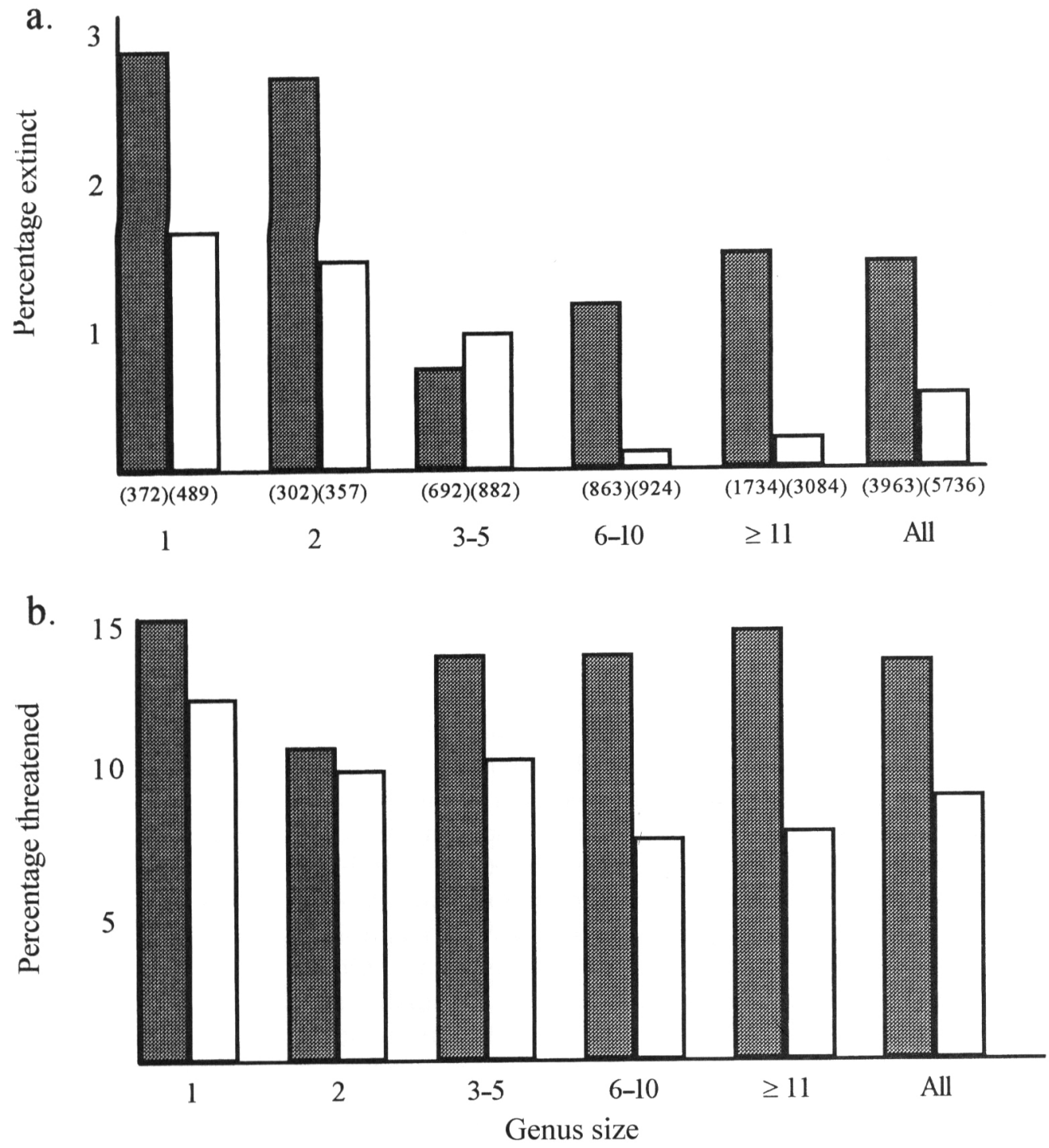

Figure 2. Percentage of historical extinction (a) and percentage threatened among extant species (b) in non-passerine (black bars) and passerine (open bars) species of birds; species are categorized according to genus size. Species numbers are shown in $a$. The proportion of extinct species in monotypic (single-species) genera was significantly greater than that in genera of more than one species for both non-passerines $(G=4.18 ; P<0.05)$ (Sokal and Rohlf 1995) and passerines $(G=8.75 ; P<0.005)$. The proportion of threatened species in monotypic genera was significantly greater than that in other genera for passerines $(G=$ 9.90; $P<0.005)$ but not for non-passerines $(G=0.67 ;$ n. s.). Overall, both the proportion extinct $(G=19.89 ; P<0.001)$ and the proportion threatened $(G=63.46 ; P<0.001)$ were significantly greater for non-passerines than for passerines. 
extinction but have a relatively low rate of current threat (Figure 1). This difference seems to be due to a high level of extinction among species in this group endemic to one or a few oceanic islands (such as the Hawaiian species in the genus Moho), as a consequence of which oceanic island endemics now constitute a lower proportion of the surviving Meliphagoidea.

Overall, the results show a pattern of anthropogenic threat that is non-uniform with regard to major phylogenetic branches of the class Aves. The fact that species in monotypic genera have been disproportionately vulnerable suggests that human activities target genetically unusual species. Species without close living relatives often inhabit unique environments that have undergone extended geographical isolation, such as oceanic islands, and such environments are generally quite vulnerable to disturbance (Johnson and Stattersfield 1990, Cronk 1997). Finally aspects of human psychology may lead humans to focus certain destructive behaviours (e.g. hunting, avicultural collecting) on unusual species.

The results showed no effect of genus size on current endangerment in nonpasserines, although there was such an effect in the case of historical extinction. This suggests some change in the way that human activities are affecting nonpasserines.

The higher levels of both historical extinction and current threat in nonpasserines than in passerines may reflect at least in part the effects of body size and fecundity differences between non-passerines and passerines. Bennett and Owens (1997) reported that risk of extinction in birds is correlated positively with body size and negatively with clutch size. A negative association between extinction risk and fecundity is predicted because a species with low fecundity will recover slowly from a reduction in population density (Pimm et al. 1988). Insofar as clutch size is correlated with fecundity in birds, the results of Bennett and Owens (1997) support this prediction. Non-passerines that have suffered high levels of extinction risk include several examples, such as the cranes, of large-bodied species with low annual fecundity. On the other hand, heavily impacted non-passerines include some much smaller species, such as many parrots. Perhaps significantly, many of the latter are relatively brightly coloured. In the case of anthropogenic effects on species survival, it is possible that some measure of conspicuousness - including both body size and coloration - may be a better predictor of risk than body size alone.

The results showed no effect of genus size on current endangerment in nonpasserines, although there was such an effect in the case of historical extinction. This suggests some change in the way that human activities are affecting nonpasserines, but there appears to be no parallel effect in the case of passerines. One possible explanation for the changed situation in non-passerines is that it reflects the overall higher levels of current threat in passerines than in nonpasserines. When endangerment becomes widespread, it may become relatively promiscuous, thereby affecting different lineages more evenly. For example, most early extinctions involved island species, many without close relatives; but an increasing percentage of continental species are among those currently endangered, and more of these may belong to species-rich genera.

It remains uncertain whether the non-uniform patterns of extinction and endangerment seen in the case of birds have parallels in the rest of the biotic world, but some evidence suggests that they may. Species of many taxa inhabit- 
ing islands or other restricted habitats have proved vulnerable (Cronk 1997). In addition the apparent human tendency to target the unusual is seen in such diverse phenomena destructive to biodiversity as the exotic pet trade, insect collecting, and the use of body products of unusual animals (e.g. rhinoceroses) in traditional medicines (Broad et al. 1988, Ryder 1993, Samways 1994). Furthermore, the study of Russell et al. (1998) shows a non-random distributon of extinction risk in mammals.

If anthropogenic extinction was random with respect to the phylogeny of life, it might be argued that any conservation strategy designed to maximize the amount of genetic diversity that is preserved would represent an unnecessary effort, since the overall effect would differ little from random extinction (Nee and May 1997). On the other hand if, as the present analyses suggest, anthropogenic extinction differentially affects different major lineages and preferentially targets species with no close relatives, it would seem prudent to devise conservation strategies to counteract these biases. These analyses thus provide a rationale for giving conservation priority toward lineages historically heavily impacted by human activities. They also provide an additional line of support for proposals to give high priority to species without close relatives (Erwin 1991, Krajewski 1991, Crozier 1992, 1997, Faith 1994).

\section{References}

Bennett, P. M. and Owens, I. P. F. (1997) Variation in extinction risk among birds: chance or evolutionary predisposition? Proc. R. Soc. Lond. B 264: 401-408.

Bibby, C. J. (1995) Recent past and future extinctions in birds. Pp. 98-110 in F. H. Lawton and R. M. May, eds. Extinction rates. Oxford: Oxford University Press.

Broad, S., Luxmoore, R. and Jenkins, M. (1988) Significant trade in wildlife: a review of selected species in CITES. Appendix II. Cambridge, U.K.: International Union for Conservation of Nature and Natural Resources.

Collar, N. J., and Juniper, A. T. (1992) Dimensions and causes of the parrot conservation crisis. Pp. 1-24 in S. R. Beissinger and N. F. R. Snyder, eds. New World parrots in crisis. Washington, DC: Smithsonian Institution Press.

Collar, N. J., Crosby, M. J., and Stattersfield, A. J. (1994) Birds to watch 2: the world list of threatened birds. Washington, DC: Smithsonian Institution Press.

Cooper, A., Atkinson, I. A. E., Lee, W. G. and Worthy, T. H. (1993) Evolution of the Moa and their effect on the New Zealand flora. Trends Ecol. Evol. 8: 433-437.

Cronk, Q. C.B. (1997) Islands: stability, diversity, conservation. Biodivers. Conserv. 6: 477493.

Crozier, R. H. (1992) Genetic diversity and the agony of choice. Biol. Conserv. 61: 11-15.

Crozier, R. H. (1997) Preserving the information content of species: genetic diversity, phylogeny, and conservation worth. Annu. Rev. Ecol. Syst. 28: 243-268.

Diamond, J. M. (1989) The present, past and future of human-caused extinctions. Phil. Trans. R. Soc. Lond. B 325: 469-477.

Erwin, T. L. (1991) An evolutionary basis for conservation strategies. Science 253: 750-752.

Faith, D. P. (1994) Genetic diversity and taxonomic priorities for conservation. Biol. Conserv. 68: 69-74.

Gaston, K. J. and Blackburn, T. M. (1997) Evolutionary age and risk of extinction in the global avifauna. Ecol. Evol. 11: 557-565.

Jablonski, D. (1986) Causes and consequences of mass extinctions: a comparative approach. Pp. 183-229 in D. K. Elliot, ed. Dynamics of extinction. New York: Wiley. 
Johnson, T. H., and Stattersfield, A. J. (1990) A global view of island endemic birds. Ibis 132: 167-18o.

Krajewski, C. (1991) Phylogeny and diversity. Science 254: 918-919.

Kunin, W. E. and Lawton, J. H. (1996) Does biodiversity matter? Evaluating the case for conserving species. Pp. 283-308 in K. J. Gaston, ed. Biodiversity: a biology of numbers and difference. Oxford: Blackwell.

McKinney, M. L. (1997) Extinction vulnerability and selectivity: combining ecological and paleontological views. Ann. Rev. Ecol. Syst. 28: 495-516.

Meine, C. and Archibald, G. W. (1996) Ecology, status, and convervation. Pp. 263-292 in D. H. Ellis, G. F. Gee and C. M. Mirande, eds. Cranes: their biology, husbandry, and conservation. Washington: U.S. National Biological Service.

Nee, S. and May, R. M. (1997) Extinction and the loss of evolutionary history. Science 278 : 692-694.

Oldfield, M. J. (1984) The value of conserving genetic resources. Washington: U.S. Department of Interior.

Pimm, S. L., Russell, G. J., Gittleman, J. L. and Brooks, T. M. (1995) The future of biodiversity. Science 269: 347-350.

Pimm, S. L., Jones, H. L. and Diamond, J. (1988) On the risk of extinction. Amer. Nat. 132: $757-785$.

Russell, G. J., Brooks, T. M., McKinney, M. M. and Anderson, C. G. (1998) Taxonomic selectivity in bird and mammal extinctions: present and future. Conserv. Biol. 12: 13651376.

Ryder, O. A. (1993) Rhinoceros biology and conservation. San Diego: San Diego Zoological Society.

Samways, M. J. (1994) Insect conservation biology. New York: Chapman and Hall.

Samways, M. J. (1996) Insects on the brink of a major discontinuity. Biodiver. Conserv. 5: $1047^{-1058 .}$

Seehausen, O, Witte, F., Katunzi, E. F., Smith, J. and Bolton, N. (1997) Patterns of remnant cichlid fauna in Lake Victoria. Conserv. Biol. 11: 890-904.

Sibley, C. G. and Ahlquist, J. E. (1990) Phylogeny and classification of the birds of the world. New Haven: Yale University Press.

Sibley, C. G. and Monroe, B. L., Jr. (1990) Distribution and taxonomy of birds of the world. New Haven: Yale University Press.

Sibley, C. G. and Monroe, B. L. Jr. (1993) A supplement to distribution and taxonomy of birds of the world. New Haven: Yale University Press.

Smith, F. D.M., May, R. M., Pellew, R., Johnson, T. M. and Walter, K. S. (1993) Estimating extinction rates. Nature 354: 494-496.

Sokal, R. R., and Rohlf, F. J. (1995) Biometry, third edition. New York: W. H. Freeman.

Vasquez, D. P. and Gittleman, J. L. (1998) Biodiversity conservation: does phylogeny matter? Curr. Biol. 8: R379-R381.

\section{AUSTIN L. HUGHES}

Department of Biology and Institute of Molecular Evolutionary Genetics, The Pennsylvania State University, University Park PA 16802 USA. E-mail: austin@hugaus3.bio.psu.edu 